\title{
Carga máxima admissível de fósforo e estado trófico do Reservatório Tanque Grande, Guarulhos - SP
}

\author{
Maximum permissible load and trophic state of Tanque Grande Reservoir, Guarulhos - SP.
}

\author{
Maíra Simões Cucioº Monica Ferreira do Amaral Porto ${ }^{2}$ \\ ${ }^{1,2}$ Universidade de São Paulo, São Paulo, SP, Brasil \\ maira.simoes@usp.br; mporto@usp.br
}

Recebido: 19/02/14 - Revisado: 01/05/14 - Aceito: 13/02/15

\begin{abstract}
RESUMO
O avanço da ocupação humana em direção às áreas periurbanas da Região Metropolitana de São Paulo representa sérios riscos aos principais mananciais de abastecimento de água dos municípios da região. A degradação da qualidade destes mananciais pode colocar em risco seu uso preponderante, que já é bastante crítico, visto que a RMSP já apresenta disponibilidade hídrica limitada, o que levou alguns municípios a procurarem formas complementares de abastecimento. O presente trabalho teve como objetivo avaliar o estado trófico e a carga máxima admissivel de fósforo do reservatório do Tanque Grande, um manancial superficial do município de Guarulhos, na Grande São Paulo, que é utilizado para abastecimento complementar do município, fornecendo água para cerca de 30.000 habitantes. Apesar de apresentar mais de 90\% da área da bacia com cobertura vegetal, poucos habitantes e poucas áreas agrícolas, dados do monitoramento da CETESB indicaram concentrações de fósforo total elevadas, o que motivou a elaboração da pesquisa. Para avaliar o estado trófico do reservatório foram empregadas as metodologias de indice de estado trófico de Lamparelli e o Trophic State Index, além do indice de estado trófico de Carlson, para comparação entre as metodologias. O resultado destes índices subsidiou a análise de carga máxima admissível, cujos resultados foram comparados à estimativas de cargas pontuais e difusas de fósforo produzidas na área da bacia. Foi possivel concluir que o reservatório tem apresentado melhora de estado trófico nos últimos anos e que é pouco provável que o processo de eutrofização esteja plenamente estabelecido no reservatório por conta de condições morfométricas, que propiciam boas condições de circulação da massa de água.
\end{abstract}

Palavras Chave: Estado trófico. Carga máxima admissivel. Fósforo. Guarulhos

\begin{abstract}
This study aimed to evaluate the trophic status and maximum permissible load of phosphorus in the Tanque Grande reservoir, which is used to supplement the water supply of Guarulhos municipality, providing water to approximately 30,000 inhabitants. Despite showing more than $90 \%$ of the basin area with vegetation cover, few residents and few agricultural areas, monitoring data by the CETESB indicated high concentrations of total phosphorus, which motivated the development of the research. To assess the trophic status of the reservoir, the trophic state index of Lamparelli and the trophic state index of Lamparelli, Cunha and Calijuri were employed. The Carlson's trophic state index was also used to compare the methodologies. The result of these indices were used in the maximum permissible load assessment, and the results were compared to estimates of point and non-point loads of phosphorus produced in the basin area. It was concluded that the reservoir has shown improvement in trophic state in recent years and it is unlikely that the process of eutrophication is fully established in the reservoir, probably because of morphometric conditions, which can provide good mixing conditions to the water body.
\end{abstract}

Keywords: Trophic state, maximum permissible load, reservoir ecology 


\section{INTRODUÇÃO}

$\mathrm{Na}$ franja urbano-rural, o crescimento urbano induz a conversão de áreas agrícolas e florestas em áreas urbanas. Forma-se um mosaico de pequenas áreas agrícolas e florestas fragmentadas por habitação e comércio recém-construídos, e residências pré-existentes acabam sendo englobadas pela expansão urbana. Nestas áreas, o desenvolvimento urbano está associado a uma série de impactos ao meio ambiente, especialmente quanto à introdução de poluentes de origem antropogênica aos ecossistemas em questão (SCHINDLER; SCHEUERELL, 2003).

São áreas com estas características onde se encontra a maior parte dos mananciais utilizados para abastecimento da Região Metropolitana de São Paulo - RMSP. Estas áreas são protegidas, primeiramente pela Lei Estadual n 898/1975, que declarou uma série de corpos hídricos e suas respectivas áreas de drenagem como áreas de proteção aos mananciais de interesse da RMSP. Posteriormente, esta lei foi complementada pela Lei Estadual $n^{\circ} 1172 / 1976$, que definiu classes de uso do solo para as áreas de proteção aos mananciais, além de usos permitidos nos corpos hídricos objeto de proteção desta Lei (São Paulo, 1975; São Paulo, 1976). Juntas, estas leis formam a Lei de Proteção aos Mananciais - LPM.

No entanto, o crescimento dos loteamentos irregulares junto às áreas de proteção de mananciais teve na própria LPM uma de suas causas. O objetivo inicial de proteção aos mananciais restringiu o uso do solo nestas áreas, resultando na baixa dos preços destas terras no mercado imobiliário e oferecendo grandes áreas para a instalação de famílias de baixa renda, sem que houvesse estrutura adequada para receber este contingente populacional (FRACALANZA; CAMPOS, 2006).

A fragilidade da LPM resultou em sua revisão, sendo então elaborada a Lei Estadual n 9866/1997 - Lei de Proteção e Recuperação dos Mananciais. Esta lei toma como referência a Política Estadual de Recursos Hídricos e define a necessidade de integração entre as políticas urbanas e a política de recursos hídricos como condição fundamental para sua efetividade. Esta lei não estabelece critérios de proteção como a LPM, mas define a criação de Áreas de Proteção e Recuperação de Mananciais - as APRM's, com legislação específica, levando em conta suas especificidades (ALVIM; BRUNA; KATO, 2008; SÃO PAULO, 1997).

No entanto, apesar da proteção oferecida legalmente por estas legislações, inevitavelmente o crescimento urbano tem atingido as áreas de proteção aos mananciais, o que se torna especialmente crítico na RMSP, por conta da baixa disponibilidade hídrica, e da necessidade de importação de água de bacias vizinhas, como é o caso do Sistema Cantareira, que importa 31 $\mathrm{m}^{3} / \mathrm{s}$ das cabeceiras do Rio Piracicaba, para garantir o abastecimento da RMSP (CBH-AT, 2002; SILVA; PORTO, 2003).

Atualmente, o Sistema Cantareira abastece cerca de 8,1 milhões de pessoas das zonas norte, centro e parte das zonas leste e oeste da capital paulista, além dos municípios de Franco da Rocha, Francisco Morato, Caieiras, Carapicuíba e São Caetano do Sul, e também de parte dos municípios de Guarulhos, Barueri e Taboão da Serra (CBH-AT, 2009). Segundo o Plano de Bacia do Alto Tietê, elaborado em 2009, não há possibilidade de ex- pandir o sistema Cantareira, que já se encontra no seu limite de exportação de água para a bacia do Alto Tietê (CBH-AT, 2009).

O município de Guarulhos, em especial, é o segundo mais populoso da Região Metropolitana de São Paulo e também do Estado de São Paulo, com 1.260.840 habitantes e taxas de crescimento demográfico superiores às médias do Estado e da RMSP (Prefeitura Municipal de Guarulhos, 2008; Seade, sd). Estima-se que em 2025 a população do município chegue a 1.534.905 habitantes, correspondendo a 6,5\% do total da RMSP (IPT; FABHAT, 2013).

Segundo Ferreira (2011), as perspectivas apontam para um crescimento significativo na demanda por abastecimento de água em Guarulhos, em decorrência do crescimento populacional significativo e também do desenvolvimento de novas atividades econômicas e novos empreendimentos habitacionais, o que pode agravar a situação de baixa disponibilidade hídrica já instalada no município. O abastecimento de água é realizado pelo Serviço Autônomo de Água e Esgoto - SAAE, que distribui água fornecida pela SABESP. Os $12 \%$ restantes correspondem ao abastecimento por poços tubulares e dois pequenos mananciais superficiais do município, os reservatórios Cabuçu e Tanque Grande, ambos localizados na região do Parque Estadual da Cantareira (PREFEITURA MUNICIPAL DE GUARULHOS, 2008).

O reservatório Cabuçu encontra-se em situação satisfatória, uma vez que tanto o reservatório quanto a bacia de contribuição estão totalmente inseridos no Parque Estadual da Cantareira, uma unidade de conservação de proteção integral, e não existe qualquer tipo de ocupação ou atividade humana na área da bacia. Já a bacia do Tanque Grande, objeto desta pesquisa, é adjacente ao Parque Estadual da Cantareira e, ao contrário do reservatório do Cabuçu, não tem a proteção oferecida pelo Parque Estadual da Cantareira.

Apesar de se localizar em uma região afastada dos centros urbanos, com baixa densidade populacional, cobertura vegetal significativa e poucas áreas com atividades agrícolas, os dados de qualidade da água do reservatório do Tanque Grande indicam alguns problemas. As concentrações de fósforo e coliformes fecais estão acima dos limites impostos nas resoluções pertinentes, o que reforça a necessidade de estabelecimento de diretrizes para compatibilizar o desenvolvimento das atividades na área da bacia à necessária proteção aos mananciais (IPT; FABHAT, 2013).

Em 2013, foi finalizado o Plano de Desenvolvimento e Proteção Ambiental dos Sistemas Isolados de Guarulhos, que consiste em um documento com um amplo diagnóstico das bacias do Cabuçu e Tanque Grande, estabelecendo diretrizes para o planejamento ambiental destas bacias e fornecendo subsídios para a formulação da Lei Específica da APRM do Cabuçu e APRM do Tanque Grande. Esta Lei Específica se encontra, atualmente, em fase de discussão e aprovação no Comitê de Bacia Hidrográfica do Alto Tietê.

Levando em consideração que a bacia do Tanque Grande apresenta algumas áreas com atividades agrícolas e atividades de lazer, e que não há coleta e tratamento de esgotos, considera-se que fontes pontuais e difusas de poluição contribuem para que as variáveis de qualidade da água do reservatório não estejam 
acordo com o enquadramento proposto do reservatório do Tanque Grande, que é utilizado para abastecimento público.

Sendo assim, o objetivo deste trabalho foi a investigação da contribuição de fontes pontuais e difusas de fósforo afluentes ao reservatório e sua relação com a carga máxima admissível de fósforo, observando o estado trófico do reservatório a partir de diferentes metodologias empíricas e observando também os cenários propostos no PDPA da APRM dos Sistemas Isolados de Guarulhos, que abrange as bacias do Cabuçu e Tanque Grande.

\section{MATERIAL E MÉTODOS}

A bacia hidrográfica do reservatório Tanque Grande faz parte da Bacia do Baquirivu-Guaçu, afluente do Rio Tietê, tem $7,8 \mathrm{~km}^{2}$ de área, e localiza-se no bairro de mesmo nome, no município de Guarulhos, conforme Figura 1. A jusante do reservatório encontra-se a ETA Tanque Grande, que tem outorga para $90 \mathrm{~L} / \mathrm{s}$ e abastece cerca de 30.000 habitantes do município (FERREIRA, 2011; IPT; FABHAT, 2013).

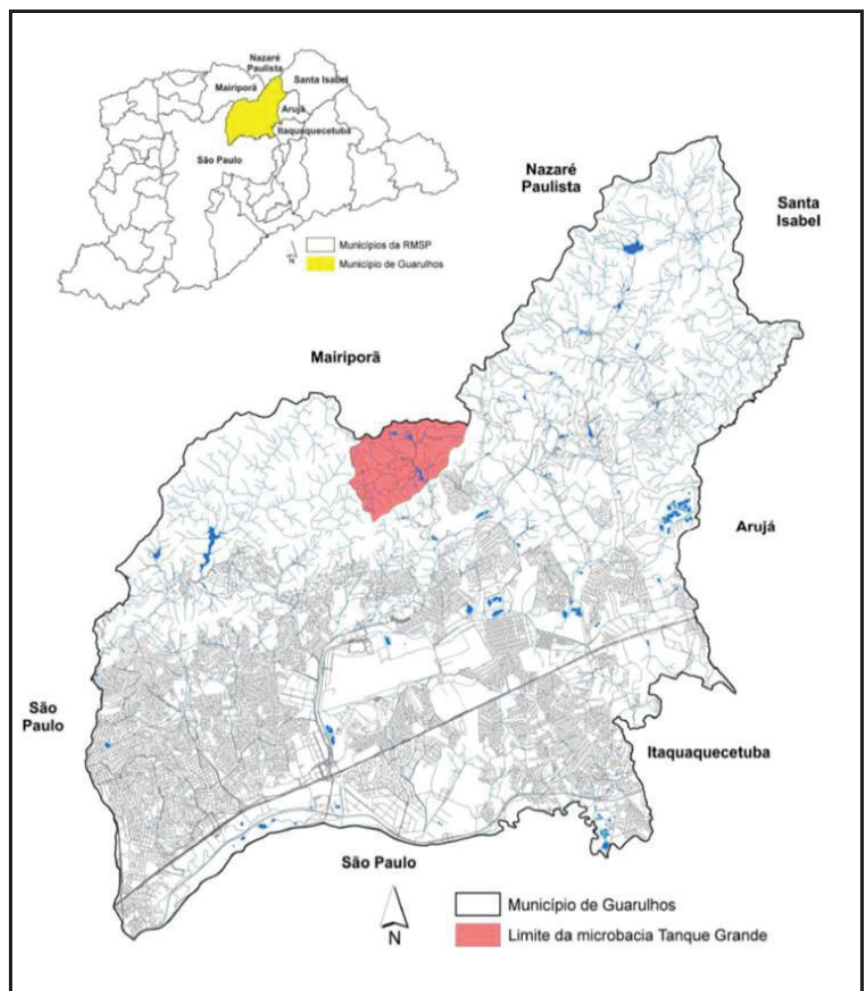

Figura 1 - Localização do município de Guarulhos em relação à RMSP e localização da bacia do Tanque Grande em relação ao município de Guarulhos

Fonte: SILVA et al, 2011

A área da bacia do Tanque Grande corresponde ao setor censitário 351880005000978, segundo o Censo 2010 do IBGE. Por estar afastado do centro da cidade, próximo ao Parque Estadual da Cantareira e com várias unidades de conservação sobrepostas, o bairro do Tanque Grande é pouco ocupado. Projeções demográficas realizadas no âmbito do PDPA dos
Sistemas Isolados de Guarulhos apontam uma população de 297 habitantes na área da bacia, no ano de 2012 (IPT; FABHAT, 2013). O Censo 2010 do IBGE apontou a existência de 90 domicílios no bairro do Tanque Grande, sendo que apenas cinco destes domicílios tinham abastecimento de água pela rede geral de abastecimento, nenhum tinha ligação à rede geral de esgotos e apenas três tinham seu lixo coletado (IBGE, 2010).

Apesar de apresentar boa parte da cobertura vegetal de mata ou reflorestamento (95,88\% da área da bacia), a presença de campos antrópicos, chácaras e estabelecimentos agropecuários podem causar alterações na qualidade das águas da bacia. Ainda, a existência de estradas, que facilitam o acesso à região, também contribui para a intensificação das atividades de lazer na região, comprometendo a qualidade da água (ANDRADE, 2009).

Uma análise da ocupação do solo na região do Tanque Grande indica usos rurais, com instalação de chácaras e casas de veraneio, além de pequenos estabelecimentos agropecuários e áreas de reflorestamento (Andrade, 2009). De acordo com Silva (2009), na área da bacia do Tanque Grande encontram-se diversos tipos de atividades, como reflorestamentos, cultivo de bambu, hortifrutigranjeiros, produção de mel, piscicultura, chácaras, dentre outras. A Figura 2 mostra o mapeamento de uso e ocupação do solo, elaborado em 2005 pela Universidade de Guarulhos.

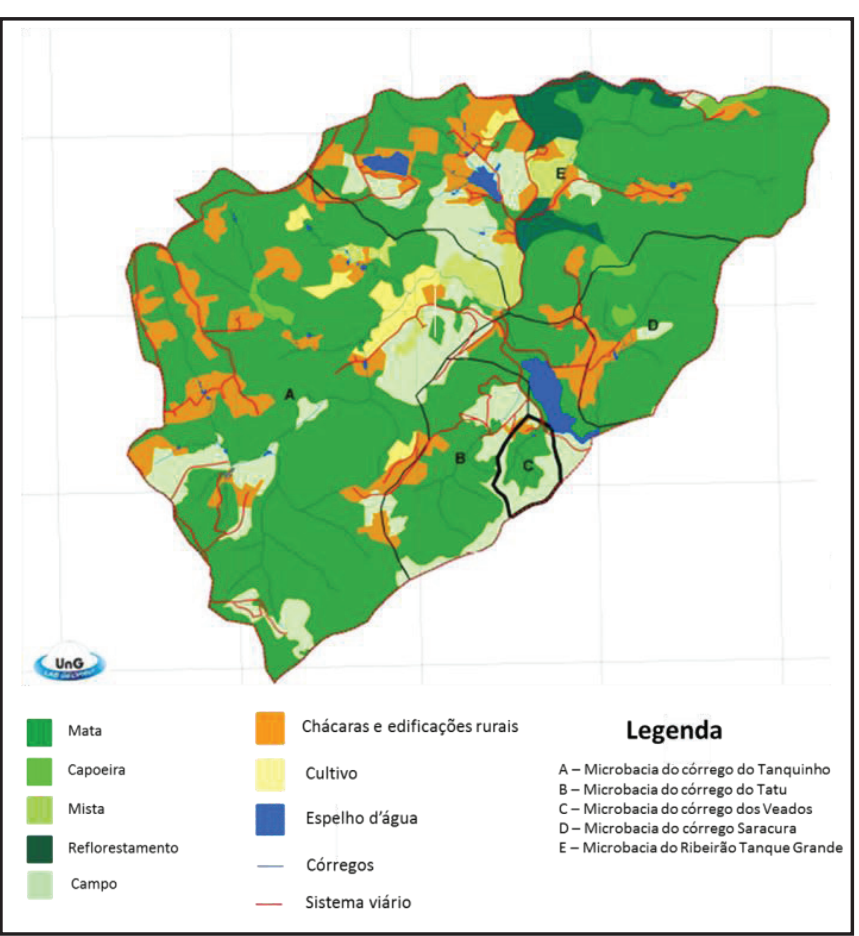

Figura 2 - Mapeamento de uso e ocupação do solo. Fonte: LABGEO, 2005

Ainda, na área da bacia foram criadas algumas unidades de conservação, como estratégia de conservação para propiciar a preservação dos remanescentes florestais e mananciais. São elas a APA Cabuçu - Tanque Grande, a Estação Ecológica Tanque Grande e o Parque Estadual do Itaberaba. 


\section{RESERVATÓRIO DO TANQUE GRANDE}

De acordo com IPT e FABHAT (2013), o reservatório do Tanque Grande tem uma área superficial de 22.159,89 $\mathrm{m}^{2}$, volume de $79.000 \mathrm{~m}^{3}$ e uma vazão média de 49L/s. O tempo de residência do reservatório foi calculado a partir dos dados de vazão e volume, resultando em 18,66 dias, aproximadamente. A profundidade média também foi calculada através da razão entre o volume e a área superficial, resultando em uma profundidade de $3,56 \mathrm{~m}$.

$\mathrm{Na}$ bacia do Tanque Grande, o monitoramento da qualidade da água, realizado pela CETESB, é feito a partir de um ponto de monitoramento no reservatório, junto à barragem. Foram encontrados dados disponíveis de qualidade da água do reservatório do Tanque Grande para o período de 2000 a 2012, totalizando treze anos de dados, com seis medições em cada ano, totalizando 78 análises.

Destas 78 análises, apenas três tiveram valores de DBO desconformes com o limite previsto na Resolução CONAMA $357 / 2005$, que é de $3 \mathrm{mg} / \mathrm{L}$ de DBO. As análises desconformes correspondem ao mês de novembro de 2001 (DBO5,20 de 5 $\mathrm{mg} / \mathrm{L}$ ), março de 2004 (DBO5,20 de $9 \mathrm{mg} / \mathrm{L}$ ) e novembro de 2010 (DBO5,20 de $5 \mathrm{mg} / \mathrm{L}$ ). Nos dados restantes a DBO se manteve sempre abaixo de $3 \mathrm{mg} / \mathrm{L}$, atendendo ao padrão estabelecido.

Já para o oxigênio dissolvido, das 78 coletas realizadas, 9 tiveram valores abaixo de $6 \mathrm{mg} / \mathrm{L}$, que é o padrão mínimo estabelecido pela Resolução CONAMA 357/2005. Os valores não chegam ser menores que $4 \mathrm{mg} / \mathrm{L}$, conforme é mostrado na Figura 3.

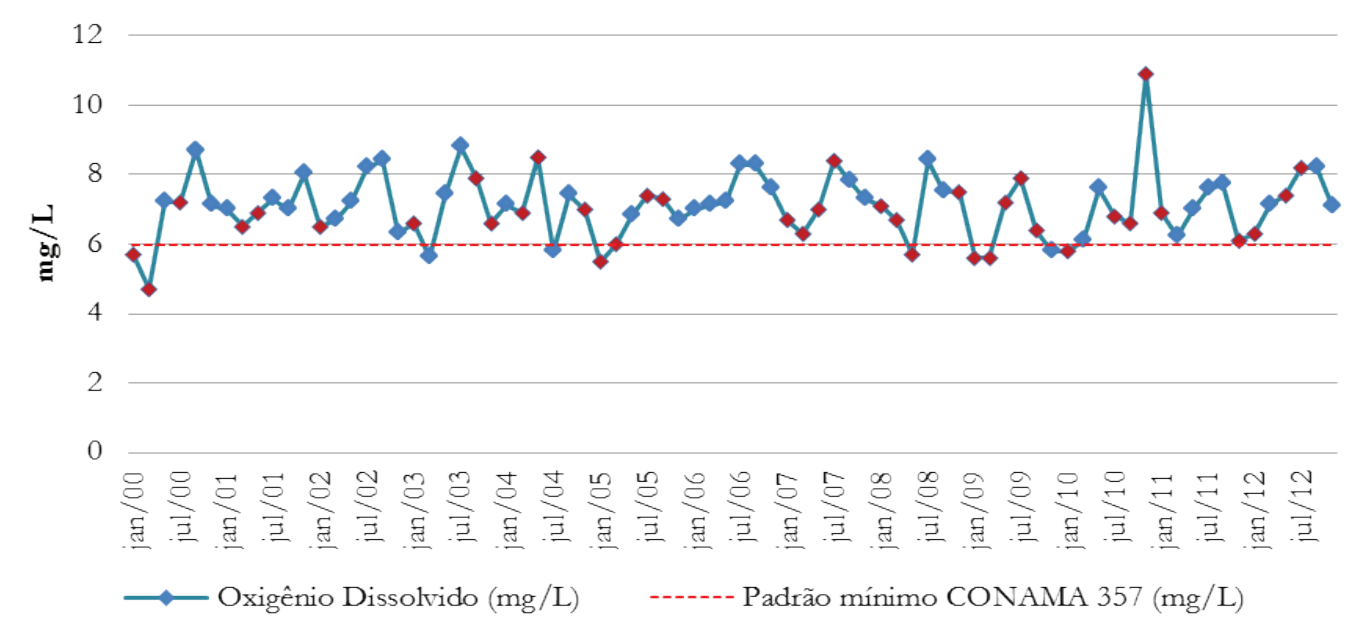

Chuva nas 24 horas anteriores

Figura 3 - Gráfico da série histórica de dados de oxigênio dissolvido. Elaboração própria através de dados da CETESB, vários anos

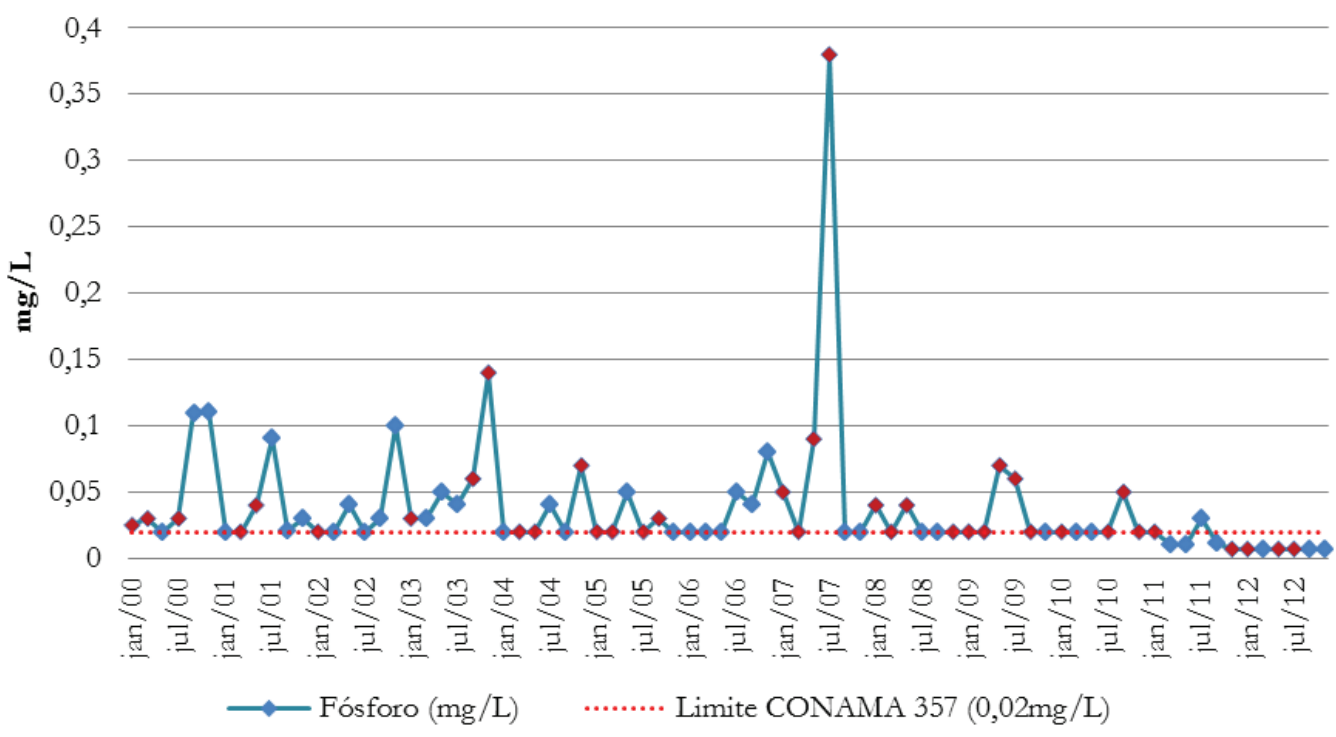

Figura 4 - Gráfico da série histórica de dados de fósforo total. Elaboração própria através de dados da CETESB, vários anos 


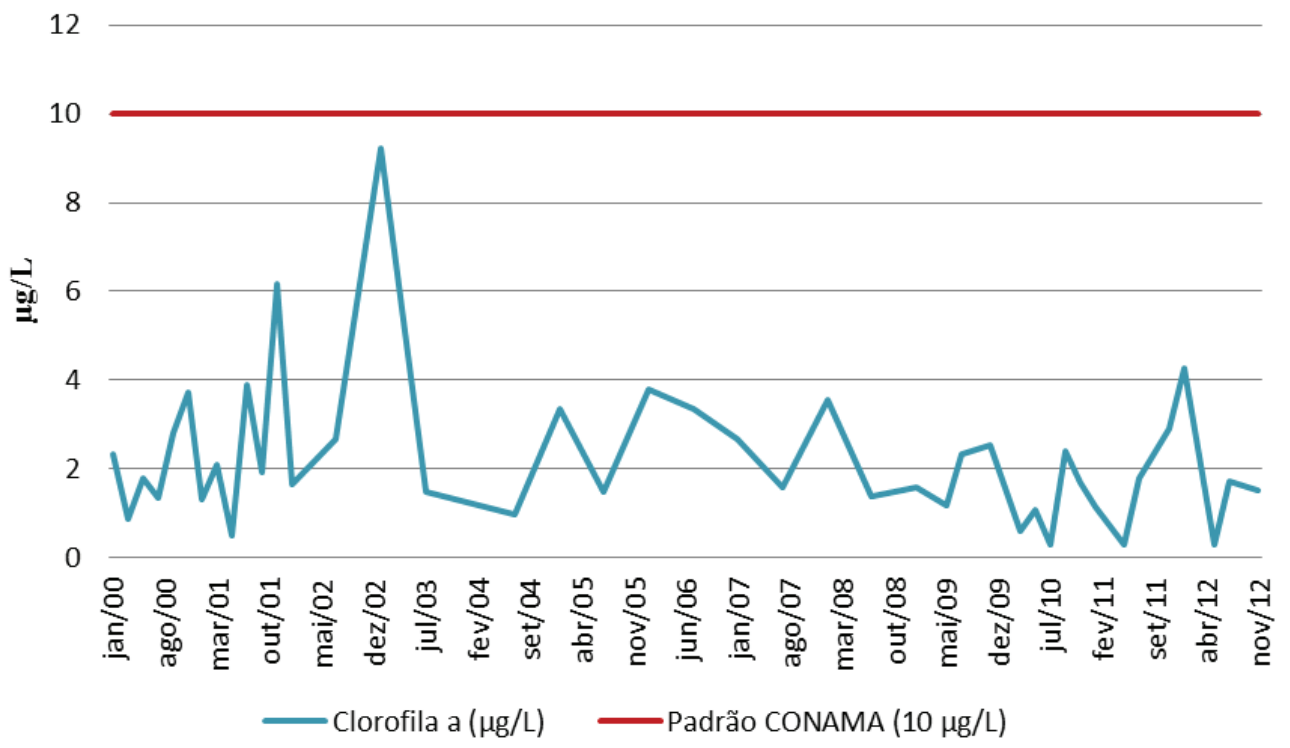

Figura 5 - Gráfico da série histórica de dados de clorofila a. Elaboração própria através de dados da CETESB, vários anos

No monitoramento de qualidade da água, são os dados de fósforo que se apresentaram mais desconformes. Do total de 78 análises, 30 delas estavam com valores acima dos limites impostos para fósforo total de acordo com a Resolução CONAMA 357/2005, que é de $0,02 \mathrm{mgP} / \mathrm{L}$ para ambientes lênticos de classe I. Também foi possível concluir que, das análises cujos resultados estavam acima do limite de fósforo total imposto pela Resolução CONAMA, metade delas apresentavam episódios de chuva nas 24 horas anteriores à coleta das amostras. Tais informações podem ser consideradas como indícios do carreamento de nutrientes em eventos de chuva. A figura 4 mostra a série de dados de fósforo disponíveis nos Relatórios de Qualidade da Água da CETESB, do ano de 2000 até o ano de 2012.

Para complementar a análise, é possível observar no gráfico (Figura 5) a série histórica de dados de clorofila a, indicadora da presença de algas.

A série de dados de clorofila a, por sua vez, não indica problemas, uma vez que todas as medições estão dentro do limite imposto pela Resolução CONAMA 357/2005, que é de $10 \mu \mathrm{g} / \mathrm{L}$ de clorofila a para a classe I, em ambientes lênticos.

\section{METODOLOGIA DE ANÁLISE DOS DADOS}

Optou-se por uma análise de cargas difusas e pontuais, de forma a estimar qual seria a contribuição da população e dos usos do solo da bacia para o aporte de fósforo ao reservatório. Por ser uma bacia ainda pouco estudada e pela falta de dados disponíveis, foi selecionado o método da unidade de carga.

Para a aplicação do método da Unidade de Carga, é preciso um mapa de uso e ocupação do solo da bacia estudada, com as classes de uso do solo e as áreas correspondentes a cada tipo de uso do solo bem definidas. Definida a área ocupada por cada tipo de uso do solo na área de estudo, procede-se ao uso dos fatores de carga, que correspondem a um valor típico de exportação de fósforo atribuído a cada tipo de uso do solo. $\mathrm{O}$ valor da área ocupada por cada tipo de uso do solo deve ser multiplicado pelo fator de carga correspondente.

Para aplicação do método da unidade de carga, optou-se pela utilização dos fatores de carga de SMA e Cobrape (2007), que apresenta fatores de carga de fósforo total e outros componentes para a bacia da Guarapiranga, Região Metropolitana de São Paulo. Este fator de carga foi escolhido pela proximidade e maior relação com a bacia do Tanque Grande, uma vez que ambas se inserem em uma região com características de uso do solo e condições climáticas semelhantes, considerando que o uso de fatores de carga locais é mais apropriado. Os fatores e carga encontram-se expressos na Tabela a seguir.

Tabela 1 - Coeficientes de exportação de SMA e COBRAPE (2007)

\begin{tabular}{|c|c|c|}
\hline Tipo de uso do solo & Unidade & $\begin{array}{c}\text { Fósforo } \\
\text { Total }\end{array}$ \\
\hline Atividade agrícola & $\mathrm{Kg} / \mathrm{km}^{2}$.dia & 0,066 \\
\hline Reflorestamento & $\mathrm{Kg} / \mathrm{km}^{2}$.dia & 0,002 \\
\hline Mata/capoeira & $\mathrm{Kg} / \mathrm{km}^{2} . \mathrm{dia}$ & 0,002 \\
\hline Capoeira/campo & $\mathrm{Kg} / \mathrm{km}^{2} \cdot \mathrm{dia}$ & 0,001 \\
\hline Chácaras & $\mathrm{Kg} / \mathrm{km}^{2}$.dia & 0,005 \\
\hline Área urbana - padrão superior & $\mathrm{Kg} / \mathrm{km}^{2} \cdot \mathrm{dia}$ & 0,136 \\
\hline Área urbana - padrão inferior & $\mathrm{Kg} / \mathrm{km}^{2} . \mathrm{dia}$ & 0,272 \\
\hline $\begin{array}{l}\text { Áreas de uso industrial e } \\
\text { comercial }\end{array}$ & $\mathrm{Kg} / \mathrm{km}^{2} \cdot \mathrm{dia}$ & 0,190 \\
\hline $\begin{array}{l}\text { População com lançamento } \\
\text { direto de esgoto nos corpos } \\
\text { hídricos }\end{array}$ & $\mathrm{Kg} /$ hab.dia & 0,0015 \\
\hline $\begin{array}{c}\text { População de áreas urbanizadas } \\
\text { com sistema individual de } \\
\text { disposição de esgotos - alta } \\
\text { densidade }\end{array}$ & $\mathrm{Kg} / \mathrm{hab} \cdot \mathrm{dia}$ & 0,0012 \\
\hline $\begin{array}{c}\text { População de áreas urbanizadas } \\
\text { com sistema individual de } \\
\text { disposição de esgotos - baixa } \\
\text { densidade }\end{array}$ & $\mathrm{Kg} /$ hab.dia & 0,00076 \\
\hline
\end{tabular}

Fonte: SMA; COBRAPE, 2007 
Para a aplicação do método da unidade de carga, foi confeccionado um mapa de uso e ocupação do solo tomando por base um mapeamento de uso e ocupação do solo elaborado em 2005 pelo Laboratório de Análise Geoambiental da Universidade Guarulhos, atualizado através de imagens de satélite do software Google Earth, com imagens do ano de 2010. O resultado pode ser visto na Figura 6.

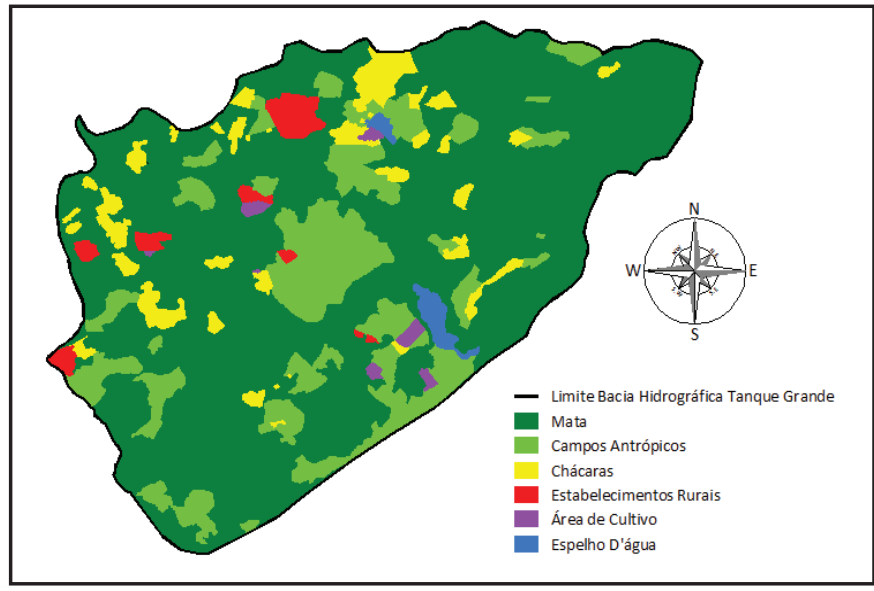

Figura 6 - Mapeamento de uso e ocupação do solo usado como base para aplicação do método da unidade de carga. Confecção própria

Com a aplicação do método da unidade de carga, esperou-se avaliar quais os tipos de uso do solo contribuem mais para a exportação de fósforo ao reservatório e qual a contribuição total de todos os usos, em $\mathrm{Kg} /$ ano.

Para estimar a quantidade de fósforo produzida por fontes pontuais na bacia, foi calculada a produção de fósforo pela população residente da bacia em questão, como apresentado no trabalho de Schaffner e Oglesby (1978). Para tanto, são necessários dados de população da bacia e quantidade média de fósforo liberada por habitante, por ano.

Após a estimativa de cargas afluentes ao reservatório, foi realizada a análise de estado trófico do reservatório, por meio de dados da série histórica disponibilizada pela CETESB, através da aplicação de três índices de estado trófico, com o objetivo de avaliar o comportamento do estado trófico do reservatório ao longo do tempo, em decorrência das concentrações de fósforo e clorofila a.

Os índices de estado trófico têm como premissas a transparência como função da biomassa fitoplanctônica; a limitação do crescimento de macrófitas e fitoplâncton por fósforo e a correlação direta entre concentração de fósforo total e a biomassa algal, tendo como base os valores de transparência medida pelo disco Secchi (SD), clorofila a (Cl a) e fósforo total (P'T) (LAMPARELLI, 2004). Cada um destes parâmetros produz uma medida diferente de estado trófico, considerada independente, constituindo um valor de IET, sendo que os valores mais altos de IET correspondem a águas de maior nível trófico (CARLSON, 1977).

Dentre os índices propostos para avaliação de estado trófico, o Trophic State Index de Carlson (1977) é o mais usado, devido à sua simplicidade e por englobar parâmetros de qualidade da água importantes quando se trata de eutrofização, permitindo avaliar de forma preliminar as condições qualitativas de um lago ou reservatório. Carlson considerou as relações empíricas entre clorofila a $(\mathrm{Cl}$ a), fósforo total (PT) e profundidade do disco secchi (SD), chegando às seguintes equações:

$$
\begin{aligned}
& \operatorname{IET}(\mathrm{Cla})=10 \cdot(6-(0,64+\operatorname{lnCla}) / \ln 2 \\
& \operatorname{IET}(\mathrm{PT})=10 \cdot(6-\ln (65 / \mathrm{PT})) / \ln 2 \\
& \operatorname{IET}(\mathrm{SD})=10 \cdot((6-\ln \mathrm{SD}) / \ln 2)
\end{aligned}
$$

Onde: $\quad \mathrm{Cla}=$ concentração de clorofila a, $\mathrm{em} \mu \mathrm{g} / \mathrm{L}$

$\mathrm{PT}=$ fósforo total, em $\mu \mathrm{g} / \mathrm{L}$

$\mathrm{SD}=$ Profundidade do Disco de Secchi

Ln $=$ Log natural

Tabela 2 - Classificação de nível trófico conforme IET de Carlson

\begin{tabular}{c|c}
\hline Nível trófico & IET \\
\hline Ultraoligotrófico & $\leq 20$ \\
\hline Oligotrófico & $21<$ IET $\leq 40$ \\
\hline Mesotrófico & $41<$ IET $\leq 50$ \\
\hline Eutrófico & $51<$ IET $\leq 60$ \\
\hline Hipereutrófico & $>61$ \\
\hline
\end{tabular}

Fonte: Carlson, 1977

Cunha, Calijuri e Lamparelli (2013) atentam para a necessidade de adaptação do IET de Carlson quando aplicado a ambientes tropicais e subtropicais, uma vez que as relações e equações estabelecidas tiveram como base ecossistemas temperados, com condições bastante diferentes dos ecossistemas tropicais e subtropicais, o que pode gerar equívocos na interpretação dos resultados obtidos ao se aplicar o IET de Carlson a tais ambientes.

Por conta disso, alguns autores como Toledo et al (1983), Lamparelli (2004) e Cunha, Calijuri e Lamparelli (2013) desenvolveram trabalhos propondo um IET modificado, obtido através de dados e condições de reservatórios tropicais (CETESB, sd; LAMPARELLI, 2004). Estes autores utilizaram uma gama de dados dos reservatórios do Estado de São Paulo para realização dos estudos, que resultaram em uma nova classificação de estado trófico baseada nas concentrações de clorofila a e fósforo total dos corpos hídricos (LAMPARELLI, 2004).

A partir das equações de Carlson e de um conjunto de dados de 24 reservatórios do Estado de São Paulo, Lamparelli (2004) propôs as seguintes equações para avaliação do estado trófico de reservatórios:

$$
\begin{aligned}
& \operatorname{IET}(\mathrm{Cl})=10 \cdot(6-((0,92-0,34 \cdot(\ln \mathrm{Cl})) / \ln 2)) \\
& \operatorname{IET}(\mathrm{P})=10 \cdot(6-(1,77-0,42 \cdot(\ln \mathrm{P}) / \ln 2))
\end{aligned}
$$

Onde: $\mathrm{Cl}=$ concentração de clorofila a, em $\mu \mathrm{g} / \mathrm{L}$

$\mathrm{P}=$ fósforo total, em $\mu \mathrm{g} / \mathrm{L}$

Ln $=$ Log natural 
Tabela 3 - Classificação de níveis tróficos do IET de Lamparelli

\begin{tabular}{|c|c|c|c|}
\hline Nível trófico & $\begin{array}{c}\text { Fósforo } \\
\text { Total }\end{array}$ & $\begin{array}{c}\text { Clorofila } \\
\mathrm{a} \\
\end{array}$ & IET \\
\hline Ultraoligotrófico & $\leq 0,08$ & $\leq 1,17$ & $\leq 47$ \\
\hline Oligotrófico & $\begin{array}{c}0,08<\mathrm{FT} \\
\leq 0,019\end{array}$ & $\begin{array}{c}1,17<\mathrm{Cl} \\
\leq 3,24\end{array}$ & $\begin{aligned} 47 & <\mathrm{IET} \\
& \leq 52\end{aligned}$ \\
\hline Mesotrófico & $\begin{array}{c}0,019< \\
\mathrm{FT} \leq \\
0,052\end{array}$ & $\begin{array}{c}3,24<\mathrm{Cl} \\
\leq 11,03\end{array}$ & $\begin{array}{c}52<\text { IET } \\
\leq 59\end{array}$ \\
\hline Eutrófico & $\begin{array}{c}0,052< \\
\mathrm{FT} \leq \\
0,120\end{array}$ & $\begin{array}{c}11,03<\mathrm{Cl} \\
\leq 30,55\end{array}$ & $\begin{array}{c}59<\mathrm{IET} \\
\leq 63\end{array}$ \\
\hline Supereutrófico & $\begin{array}{c}0,120< \\
\mathrm{FT} \leq \\
0,233\end{array}$ & $\begin{array}{c}30,55<\mathrm{Cl} \\
\leq 69,05\end{array}$ & $\begin{array}{c}63<\text { IET } \\
\leq 67\end{array}$ \\
\hline Hipereutrófico & $>0,233$ & $>69,05$ & $>67$ \\
\hline
\end{tabular}

Fonte: Lamparelli, 2004

Cunha, Calijuri e Lamparelli (2013), por sua vez, propuseram um novo ajuste aos índices de estado trófico anteriores, levando em consideração os seis níveis tróficos considerados por Lamparelli (2004). Para realização do estudo foram selecionados 18 reservatórios do Estado de São Paulo, com séries históricas de dados de fósforo total, clorofila a e turbidez (profundidade do disco de Secchi), provenientes da rede de monitoramento da CETESB, de 1996 a 2009. As equações resultantes para fósforo total e clorofila a e a tabela com a classificação trófica correspondente estão dispostas a seguir:

$$
\text { TSI }(\mathrm{TP})=10 \cdot(6-(-0,27637 \ln \mathrm{TP}+1,329766) / \ln 2)
$$

TSI $($ Chl a $)=10 .(6-(-0,2512 \operatorname{lnChl} \mathrm{a}+0,842257) / \ln 2)(7)$

Onde: $\quad \mathrm{Chl} \mathrm{a}=$ concentração de clorofila $\mathrm{a}, \mathrm{em} \mu \mathrm{g} / \mathrm{L}$

PT $=$ fósforo total, em $\mu \mathrm{g} / \mathrm{L}$

$\mathrm{Ln}=\mathrm{Log}$ natural

Tabela 4 - Classificação trófica do TSItsr

\begin{tabular}{c|c}
\hline Nível trófico & IET \\
\hline Ultraoligotrófico & $\leq 51,1$ \\
\hline Oligotrófico & $51,2<$ IET $\leq 53,1$ \\
\hline Mesotrófico & $53,2<$ IET $\leq 55,7$ \\
\hline Eutrófico & $55,8<$ IET $\leq 58,1$ \\
\hline Supereutrófico & $58,2<$ IET $\leq 59$ \\
\hline Hipereutrófico & $>59,1$ \\
\hline
\end{tabular}

Fonte: Cunha, Calijuri, Lamparelli, 2013

Por fim, foi analisada a carga máxima admissível de fósforo ao reservatório levando em consideração os resultados obtidos na análise de estado trófico e informações obtidas através da avaliação das cargas de fósforo afluentes ao reservatório.

Para o cálculo da carga máxima admissível, foi utilizada a equação resultante do modelo de Salas e Martino (1991, 2001). A carga máxima admissível consiste em uma carga de nutrientes, geralmente fósforo, calculada com base em uma concentração desejável de fósforo no corpo hídrico para que este continue mantendo seus usos preponderantes (VON SPERLING, 2005). Para o cálculo da carga máxima admissível ao reservatório do Tanque Grande, foi utilizada a seguinte equação:

$$
\mathrm{L}=\operatorname{P.V} \cdot(1 / \mathrm{t}+2 / \sqrt{\mathrm{t}}) / 10^{3}
$$

Para aplicação desta equação, é necessário que o valor de fósforo total se situe abaixo do limite da eutrofia, ou que seja utilizado o valor máximo de fósforo permitido nas resoluções CONAMA. A fixação de um valor ideal de fósforo deve ser feita caso a caso, analisando-se os usos múltiplos do reservatório e seu grau de importância (VON SPERLING,1996).

O cálculo da carga máxima admissível teve como objetivo a comparação com as cargas pontuais, de forma a subsidiar o planejamento ambiental na bacia, tendo em vista a continuidade do uso preponderante do reservatório do Tanque Grande como importante manancial do município de Guarulhos.

\section{RESULTADOS E DISCUSSÃO}

Para aplicação do método da unidade de carga, foram medidas as áreas ocupadas por cada classe de uso do solo, em hectares. Posteriormente, foi aplicado o método, que consiste na multiplicação da área ocupada por cada tipo de uso do solo pelo fator de carga correspondente, conforme Tabela 5.

Tabela 5 - Aplicação do método da Unidade de Carga

\begin{tabular}{cccc}
\hline $\begin{array}{c}\text { Tipo de uso do } \\
\text { solo }\end{array}$ & Área ocupada & $\begin{array}{c}\text { Fator de } \\
\text { carga }\end{array}$ & $\begin{array}{c}\text { Total anual de } \\
\text { emissão de fósforo } \\
\text { total } \\
\text { (em Kg) }\end{array}$ \\
\hline Mata & 217 hectares & 0,002 & 1,5841 \\
\hline $\begin{array}{c}\text { Campos } \\
\text { antrópicos }\end{array}$ & 6,78 hectares & 0,001 & 0,024455 \\
\hline $\begin{array}{c}\text { Chácaras } \\
\text { rurais }\end{array}$ & 0,40 hectares & 0,005 & 0,0073 \\
\hline Cultivos & 2,04 hectares & 0,0966 & 0,4818 \\
\hline & Total hectares & 0,066 & 0,021681 \\
\hline
\end{tabular}

Foi possível perceber que as áreas de mata foram responsáveis pela maior exportação de fósforo na bacia, não pelo potencial produtor de fósforo, mas pela magnitude em tamanho destas áreas, pois os fatores de carga correspondentes às áreas de mata são os mais baixos e mais de 95\% da área da bacia é ocupada por mata. Em segundo lugar ficaram as áreas de estabelecimentos rurais, que apesar de ocuparem apenas $0,9 \%$ da área total da bacia, contribuem com a emissão de $480 \mathrm{~g}$ de fósforo anuais. As exportações mais baixas encontradas foram de chácaras, também por conta da pequena área ocupada por este tipo de ocupação e pelo baixo fator de exportação associado.

A avaliação de cargas pontuais foi realizada através da quantificação da população residente na bacia, a quantidade de 
esgotos gerada por esta população e a concentração média de fósforo nos esgotos. Foi considerada uma população de 297 habitantes, estimada para o ano de 2012, conforme a Minuta do Plano de Desenvolvimento e Proteção Ambiental (PDPA) dos Sistemas Isolados de Guarulhos.

Considera-se que cada pessoa gera, em média, 100L de esgoto bruto por dia (ARAÚJO, 2000). Portanto, seriam gerados, pela população total da bacia, $29.700 \mathrm{~L}$ de esgoto por dia, ou $29,7 \mathrm{~m}^{3}$ de esgoto. Considerando que, segundo Piveli e Kato (2005) e Von Sperling (2005), o esgoto sanitário brasileiro tem de 6 a $10 \mathrm{mg}$ P-L, a contribuição per capita de fósforo pode ser obtida através da multiplicação da média de fósforo contida no esgotamento sanitário produzido pela população residente. Considerando uma média de $8 \mathrm{mg} / \mathrm{L}$ de fósforo e $29.700 \mathrm{~L}$ de esgoto produzidos por dia na bacia do Tanque Grande, têm-se o total de $23,76 \mathrm{~g}$ de fósforo produzidos pela população da bacia, por dia, ou 8,67 kg por ano.

A avaliação do estado trófico, por sua vez, foi realizada através de três índices de estado trófico: o IET de Lamparelli (2004), o TSItsr de Cunha, Calijuri e Lamparelli (2013), ambos modificados e adaptados a lagos e reservatórios do Estado de São Paulo, e também o IET de Carlson, para comparação entre

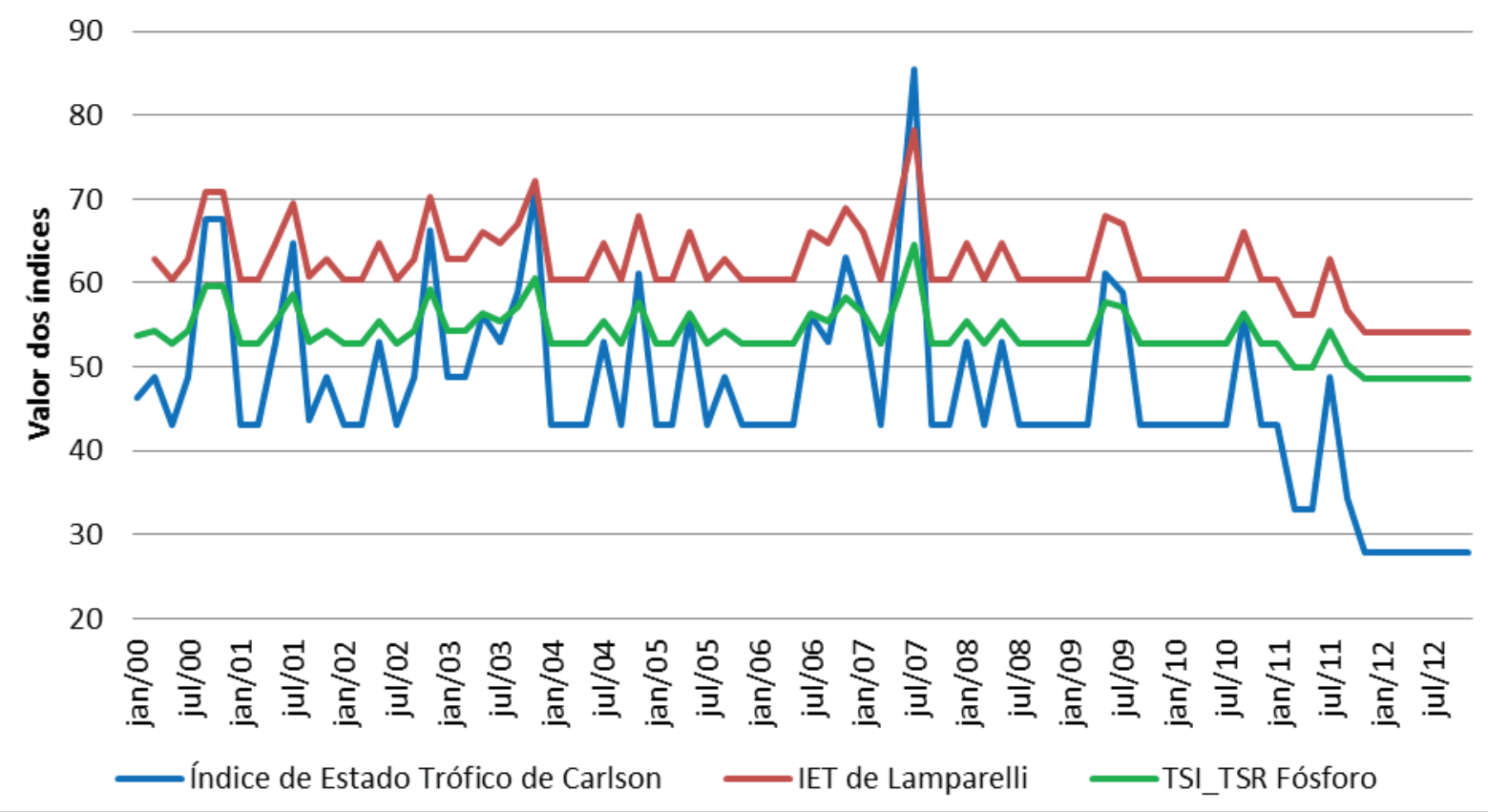

Figura 7 - Sobreposição dos resultados da aplicação dos IETs à série histórica de dados de fósforo total

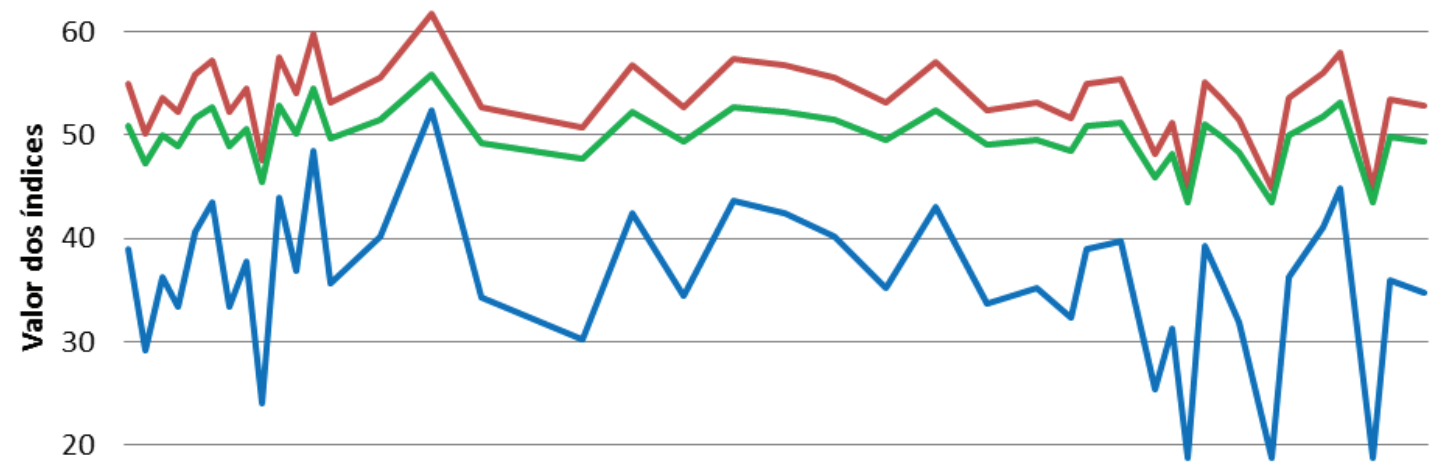

10

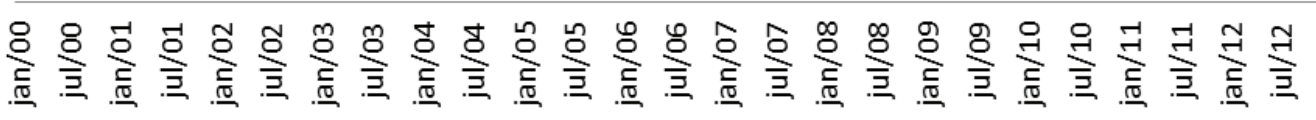

—Índice de Estado Trófico de Carlson —IET de Lamparelli —TSI_TSR Clorofila a

Figura 8 - Sobreposição dos resultados da aplicação dos IETs à série histórica de dados de clorofila a. 
os resultados. As equações dos três IETs foram aplicadas à série histórica de dados de fósforo e de clorofila a, de forma a avaliar as variações do estado trófico ao longo do tempo.

A aplicação do IET de Lamparelli para a série de fósforo mostrou que o estado trófico do reservatório variou, entre janeiro de 2000 e julho de 2010 , entre eutrófico, supereutrófico e hipereutrófico, apresentando melhora após este período, chegando a estabilizar no estado mesotrófico a partir de 2011. A aplicação deste mesmo IET à série de dados de clorofila a mostrou uma predominância do estado mesotrófico, sendo que a partir de 2009, o reservatório passou a atingir níveis oligotróficos de forma mais constante.

Assim como o IET de Lamparelli, foi também aplicado o TSItsr à série histórica de dados. Para os dados de fósforo, percebe-se que até janeiro de 2011, o estado trófico varia entre mesotrófico e eutrófico, chegando até o estado hipereutrófico em algumas situações. A partir de 2011, houve uma diminuição da concentração de fósforo, causando uma melhora no estado trófico, que atingiu os estados oligotrófico e ultraoligotrófico. Para os dados de clorofila a, as oscilações apareceram com menor intensidade, com alternância entre estado oligotrófico e ultraoligotrófico, com apenas 3 dados indicando estado mesotrófico. A partir do ano de 2008, os dados indicam diminuição desta alternância, com predomínio de estado ultraoligotrófico.

Por fim, foi aplicado também o IET de Carlson à série histórica de fósforo total, cuja aplicação mostrou que, de acordo com a classificação proposta, o reservatório do Tanque Grande variou de mesotrófico a eutrófico até o ano de 2011, com alguns picos de concentração levando à hipereutrofia. Após 2011, as concentrações de fósforo diminuem e o estado trófico varia de mesotrófico a oligotrófico. Já a aplicação do IET de Carlson para a série histórica de clorofila a mostrou predominância do estado oligotrófico, com algumas situações de mesotrofia e com apenas uma elevação da concentração de clorofila a elevando o estado trófico para eutrófico. Os gráficos das Figuras 7 e 8 mostram o resultado da aplicação dos três IETs à série histórica de fósforo e clorofila a.

Para o cálculo da carga máxima admissível, são necessários dados de tempo de retenção, volume do reservatório e concentração desejável de fósforo a se manter no corpo hídrico, conforme equação 8. O tempo de retenção foi calculado através da seguinte equação:

$$
\begin{aligned}
& \mathrm{TR}=\mathrm{V} / \mathrm{Q} \\
& \mathrm{TR}=79000 \mathrm{~m}^{3} / 0,049 \mathrm{~m}^{3} \mathrm{~s}-1.86400 \\
& \mathrm{TR}=18,66 \text { dias }
\end{aligned}
$$

O volume do reservatório, de $79.000 \mathrm{~m}^{3}$, foi obtido de IPT e FABHAT (2013), e para a concentração desejável de fósforo total, foi adotado o valor de $0,01 \mathrm{mgP} / \mathrm{L}$. A adoção deste valor se baseia nos cálculos do IET de Lamparelli (2004) e do TSItsr de Cunha, Calijuri e Lamparelli (2013), pois foi a partir deste valor que a aplicação dos IETs resultou em níveis oligotróficos e ultraoligotróficos. A aplicação destes índices em situações com a concentração de fósforo de $0,02 \mathrm{mg}-\mathrm{P} / \mathrm{L}$ resultou em níveis mesotrófico e eutrófico. Considera-se, portanto, que este é um valor mais adequado para a manutenção da qualidade da água para abastecimento.

Aplicando os valores supracitados à equação da carga máxima admissível, foi possível chegar ao valor de 22,86 kg-P/ ano admissíveis ao reservatório, que corresponde a $0,062 \mathrm{~kg}-\mathrm{P} /$ dia, um pouco menos da metade da carga meta proposta pelo PDPA da APRM do Tanque Grande, que é de $0,12 \mathrm{~kg}-\mathrm{P} / \mathrm{dia}$.

Considerando a aplicação do método da unidade de carga, que resultou em um total de $2,11 \mathrm{kgP} /$ ano exportados pelos diferentes tipos de uso do solo da bacia, é possível dizer que este valor corresponde a um aporte baixo de fósforo, bastante abaixo da carga máxima admissível calculada, que foi de $22,86 \mathrm{kgP} /$ ano.

O cálculo das cargas pontuais resultou em uma carga de 23,76g-P/dia, perfazendo um total de $8,67 \mathrm{~kg}-\mathrm{P} /$ ano. Este valor também fica abaixo da carga máxima admissível calculada para o reservatório. As cargas pontuais e difusas calculadas não atingem metade da carga máxima admissível calculada.

É preciso considerar, no entanto, que para o cálculo das cargas pontuais foi considerada apenas a população humana da bacia. Por ter áreas agrícolas, com criação de animais, seria adequado considerar também a população animal, que tem potencial de produção de fósforo significativo. Sabe-se que na bacia do Tanque Grande se desenvolvem atividades de criação de gado e aves, além de piscicultura, que tem potencial de produção de fósforo. Não foram encontrados dados da população animal na bacia, o que complementaria a análise de fontes pontuais e difusas.

Também é preciso considerar que cerca de $90 \%$ dos domicílios, atualmente, têm como solução de esgotamento sanitário as fossas rudimentares, que compreendem sistemas rústicos de encaminhamento de esgotos, e que podem ocasionar contaminação de lençol freático e corpos hídricos próximos. Não se sabe a eficiência de remoção de fósforo que estes sistemas apresentam, tampouco a quantidade de fósforo dos dejetos que seria passível de atingir os corpos hídricos da bacia, mas considera-se que seja significativo o risco de contaminação pois, geralmente, trata-se de sistemas que propiciam a infiltração dos efluentes no solo.

Schindler e Scheuerell (2003) realizaram estudo na região de Seattle, nos Estados Unidos, avaliando o nível trófico de diferentes lagos e reservatórios com diferentes condições de entorno e de saneamento. Os autores dividiram os reservatórios em três tipos: reservatórios não-desenvolvidos, correspondendo àqueles cujas bacias hidrográficas não apresentavam ocupação humana e pressões antrópicas; reservatórios com tratamento de esgoto, correspondendo àqueles cujas ocupações tinham, em sua maioria, coleta e tratamento de esgotos adequado; e reservatórios com sistemas sépticos, correspondendo àqueles cujas ocupações tinham, em sua maioria, sistemas individuais de fossa séptica como alternativa de esgotamento sanitário. Os autores utilizaram como parâmetros para avaliar a eutrofização dos corpos hídricos estudados, a concentração de fósforo no epilímnio e hipolímnio, a concentração de clorofila a no epilímnio e a proporção de fitoplâncton não comestível.

Os resultados da pesquisa indicaram que em lagos e 
reservatórios cujos sistemas de esgotamento sanitário se dava por fossas sépticas, as concentrações de fósforo no hipolímnio eram 108\% maiores do que em lagos e reservatórios com coleta e tratamento de esgoto. Lagos e reservatórios com sistemas de fossas sépticas nas ocupações do entorno também apresentaram concentrações $47 \%$ mais altas de fósforo no epilímnio em comparação com lagos e reservatórios com coleta e tratamento de esgotos nas ocupações do entorno. As concentrações de clorofila a no epilímnio também foram $174 \%$ maiores nestes lagos e reservatórios em comparação com lagos e reservatórios com sistemas de coleta e tratamento de esgotos (SCHINDLER; SCHEUERELL, 2003). Tais dados indicam a diferença que os sistemas de esgotamento sanitário disponíveis nas ocupações da bacia hidrográfica podem ocasionar na qualidade da água dos reservatórios. Os autores destacam que lagos e reservatórios cujos sistemas de esgotamento eram de fossas sépticas apresentaram maiores valores de todos os indicadores utilizados para avaliação de estado trófico, tendendo, portanto, ao estado eutrófico. Tal situação não ocorreu com lagos e reservatórios cujos sistemas de esgotamento sanitário compreendiam coleta e tratamento de esgotos.

Dados os resultados desta pesquisa, Schindler e Scheuerell (2003) consideram que o fenômeno da eutrofização é mais acentuado nas zonas periurbanas, e destacam que a forma como a ocupação se desenvolve nestas áreas é mais importante em termos de interferências na qualidade da água do que a magnitude desta ocupação. Ou seja, mesmo que a ocupação em uma bacia hidrográfica seja expressiva, se esta ocupação se estabelecer com sistema adequado de coleta e tratamento de esgotos, sistema adequado de gestão dos resíduos sólidos e sistema adequado de drenagem, as interferências na qualidade da água dos corpos hídricos da bacia em questão serão mínimas. No entanto, se uma bacia for pouco ocupada, mas não tiver gestão adequada do esgotamento sanitário, dos resíduos sólidos e da drenagem, problemas de qualidade da água, como a eutrofização, irão ocorrer.

Neste contexto se encaixa a bacia do Tanque Grande, que tem uma ocupação pouco expressiva na área da bacia, mas sem estrutura adequada de saneamento, pode ocasionar problemas de qualidade da água. Considerando que o Tanque Grande é um reservatório característico de rio de baixa ordem, conforme o Conceito do Contínuo Fluvial, e localiza-se em região montanhosa, pouco afetada pelo desenvolvimento, alimentado por vazões ainda baixas, espera-se que o reservatório tenha condições oligotróficas, com níveis pequenos de matéria orgânica e sais nutrientes, baixa temperatura e plâncton escasso (TUNDISI; MATSUMURA-TUNDISI, 2008), no entanto, o que se tem é um corpo hídrico com níveis mais altos de fósforo em determinadas épocas, o que exige maior investigação das possíveis fontes de nutrientes.

Quanto aos índices de estado trófico, é preciso considerar que o IET referente ao fósforo deve ser entendido como medida do potencial de eutrofização, e o IET referente à clorofila a deve ser entendido como a resposta do corpo hídrico ao agente causador, no caso, o fósforo. Ainda, nos corpos hídricos cujo processo de eutrofização esteja plenamente estabelecido, os índices referentes ao fósforo e à clorofila a coincidem, indicando o mesmo estado trófico. No entanto, em corpos hídricos cujo processo de eutrofização esteja sendo limitado por outros fatores, como temperatura ou turbidez, o IET $(\mathrm{Cl})$ irá classificar o corpo hídrico em um nível trófico inferior àquele determinado pelo IET (P)(Cetesb, sd).

$\mathrm{Na}$ aplicação dos três índices de estado trófico utilizados, os resultados acusaram valores maiores de IET $(\mathrm{P})$ e menores de IET $(\mathrm{Cl})$, o que indica que o processo de eutrofização não está plenamente estabelecido. No caso da aplicação do IET de Carlson, o IET (P) indica nível trófico ligeiramente mais elevado do que o IET $(\mathrm{Cl})$, indicando que os aumentos dos níveis de fósforo não necessariamente causaram aumento da biomassa algal. Na aplicação do IET de Lamparelli, os resultados também se mostraram diferentes para o IET (P) e o IET $(\mathrm{Cl})$, não resultando no mesmo estado trófico, e na aplicação do TSI TSR, o TSI $(\mathrm{P})$ indica nível trófico ligeiramente mais elevado do que o TSI (Cl), no entanto, houve três situações em que o TSI coincidiu, indicando mesmo estado trófico, o que pode indicar um início de processo de eutrofização em curso.

De forma geral, é possível notar que a aplicação dos três IETs permitiu avaliar que o processo de eutrofização do reservatório pode estar sendo influenciado por fatores não-nutriente, visto que, mesmo em situações em que as concentrações de fósforo são altas e resultam em um IET (P) eutrófico ou hipereutrófico, o IET $(\mathrm{Cl})$ não reflete esta condição, se mantendo em níveis oligotróficos e mesotróficos.

Uma questão que pode ter influência nos resultados dos índices de estado trófico, é que o conjunto de dados utilizado é composto apenas de dados provenientes de coletas de superfície, e da zona lacustre dos reservatórios, próximo à barragem. A ausência de coletas em diferentes profundidades, no epilímnio e hipolímnio, e em outras zonas horizontais do reservatório (zona de transição e zona riverina), poderia interferir nos resultados obtidos, uma vez que as concentrações de fósforo podem ser ligeiramente diferentes nas zonas horizontais e verticais do reservatório, permitindo comparação entre os resultados e complementando a análise.

Schindler e Scheuerell (2003), por exemplo, utilizaram como parâmetros para avaliar a eutrofização dos corpos hídricos estudados, a concentração de fósforo no epilímnio e hipolímnio, a concentração de clorofila a no epilímnio e a proporção de fitoplâncton não comestível, o que reforça a importância da realização de um monitoramento de qualidade da água em diferentes zonas verticais e horizontais do reservatório. Caso estes dados estivessem disponíveis, seria possível realizar uma análise da eutrofização do reservatório de forma mais abrangente e completa. Com a avaliação de diferenças nas concentrações de fósforo do epilímnio e hipolímnio, poderia ser avaliada também a questão do internal loading, ou seja, da liberação de fósforo pelo hipolímnio, aumentando a concentração de fósforo na massa d'água.

\section{CONCLUSÕES}

Tanto os métodos da unidade de carga como o método de cálculo de fontes pontuais representaram bons resultados e fácil aplicação, tendo em vista a escassez de dados da bacia. 
Através do cálculo da carga máxima admissível ao reservatório do Tanque Grande foi possível concluir que as cargas pontuais e difusas juntas, ficam abaixo da carga máxima admissível calculada. No entanto, é preciso considerar que não foi considerada a população animal da bacia, e que a maior parte dos domicílios não tem sistema adequado de destinação de esgotos.

No entanto, dados dos relatórios de qualidade da água da CETESB apontam para dados elevados de fósforo total. Considerando os valores elevados de fósforo no reservatório, principalmente em anos anteriores, é possível que esta carga esteja sendo excedida por conta de outros fatores, como internal loading, atividades de recreação no reservatório, criação de animais, dentre outros, que não puderam ser considerados no presente trabalho. Seria, portanto, recomendável, que estudos futuros levem em conta estes fatores, com uma análise mais abrangente.

A aplicação dos índices de estado trófico, por sua vez, permitiu verificar que, com uma diminuição das concentrações de fósforo no reservatório nos últimos 3 anos, houve melhora do estado trófico. Ainda, foi possível perceber que os índices referentes ao fósforo total não coincidiam com os índices referentes à clorofila a, o que indica que o processo de eutrofização não está plenamente estabelecido no reservatório, e pode estar sendo limitado por fatores não-nutriente.

Com a profundidade de 3,56m, o Tanque Grande é considerado um reservatório raso. Em lagos e reservatórios de baixa profundidade, a radiação solar pode chegar a atingir o fundo, o que implica na possibilidade de ocorrência de produtividade primária por toda a coluna d'água. Por ter um tempo de residência de 18 dias, intermediário, mas baixo, é possível inferir que o reservatório apresenta características mais próximas à de rios.

Tanto a baixa profundidade como o tempo de residência baixo indicam boas condições de circulação no reservatório, que propiciam a oxigenação pela possibilidade de produtividade primária em toda a coluna d'água e pouca probabilidade de ocorrência de estratificação, que provocaria uma estagnação das massas de água, dificultando a oxigenação. Tais inferências podem ser confirmadas analisando-se os dados de oxigênio dissolvido no reservatório apresentam-se satisfatórios em quase todas as análises.

Através destes dados, é possível inferir que estes dois fatores, tempo de residência e profundidade, talvez sejam os fatores não-nutriente relacionados ao não estabelecimento pleno do processo de eutrofização, verificado através da aplicação dos índices de estado trófico. Com condições favoráveis de circulação, e rápida renovação da água do reservatório, a instauração do processo de eutrofização fica dificultada.

\section{REFERÊNCIAS}

ALVIM, A.T. B; BRUNA, G. C; KATO, V. R. C. Políticas ambientais e urbanas em áreas de mananciais: interfaces e conflitos. Cadernos Metrópole, São Paulo, v. 19, p. 143-164, jul. 2008.

ARAÚJO, L. F. P. Reúso com lagoas de estabilização: potencialidade do Ceará. Fortaleza: SEMACE, 2000.
CARLSON, R. E. A trophic state index for lakes. Limnology and Oceanography. n. 22, p. 361-369, 1977.

COMPANHIA AMBIENTAL DO ESTADO DE SÃO PAULO - CETESB. IET - Índice do Estado Trófico. Disponível em: http:/ / www.cetesb.sp.gov.br/userfiles/file/agua/aguas-superficiais/ aguas-interiores/documentos/indices/04.pdf. Acesso em: 24 de set. 2013.

COMITÊ DE BACIA HIDROGRÁFICA DO ALTO TIETÊ - CBH-AT. Plano da Bacia Hidrográfica do Alto Tietê: Sumário Executivo. São Paulo: FUSP, 2009.

CUNHA, D.G. F.; CALIJURI, M. C.; LAMPARELLI, M. C. A trophic state index for tropical/subtropical reservoirs (TSItsr). Ecological Enginnering. n. 60, p. 126-134, 2013.

FERREIRA, R. S. Gestão de Águas Urbanas em Guarulhos. 2011, 160f. Dissertação (Mestrado em Engenharia Civil) - Escola Politécnica, Universidade de São Paulo, São Paulo, 2011.

FRACALANZA, A.P.; CAMPOS, V.N.O. Produção social do espaço urbano e conflitos pela água na Região Metropolitana de São Paulo. São Paulo em Perspectiva. São Paulo, Fundação Seade, v. 20, n. 2, p. 32-45, abr./jun. 2006.

LAMPARELLI, M. C. Grau de trofia em corpos d'água do Estado de São Paulo: Avaliação dos Métodos de Monitoramento. São Paulo. 2004. 238f. Tese (Doutorado) - Instituto de Biociências, Universidade de São Paulo, São Paulo, 2004.

SÃO PAULO. Lei Estadual n 898 de $1^{\circ}$ de novembro de 1975. Dispõe sobre a criação da Lei de proteção aos mananciais da região metropolitana de São Paulo.

SÃO PAULO. Lei Estadual n 1.172 de 17 de novembro de 1976. Delimita as áreas de proteção relativas aos mananciais, cursos e reservatórios de água, a que se refere o artigo $2^{\circ}$ da Lei Estadual n $^{\circ}$ 898, 18 de dezembro de 1975, estabelece normas de restrição do uso do solo em tais áreas e dá providências correlatas.

SÃO PAULO. Lei Estadual n 9.866 de 28 de novembro de 1997. Dispõe sobre diretrizes e normas para a proteção e recuperação das bacias hidrográficas dos mananciais de interesse regional do Estado de São Paulo, e dá outras providências.

SCHINDLER, D.E.; SCHEUERELL, M.D.; FRODGE, J. Lake eutrophication at the urban fringe, Seattle Region, USA. Ambio, v. 32, p. 13-18, 2003.

SCHLOGL, A. K. S. B. A lei de proteção aos mananciais e mercados de terras: um estudo sobre loteamentos clandestinos. 2004. Dissertação (Mestrado) - Instituto de Economia, Universidade Estadual de Campinas, Campinas, 2004.

SILVA, C.; OLIVEIRA, A. M. S.; FIGUEIRA, R. C. L.; SEMENSATTO, D.; LABUTO, G. Estudo do assoreamento 
RBRH vol. 20 no.3 Porto Alegre jul./set. 2015 p. 677 - 688

do reservatório tanque grande, Guarulhos (SP). Revista Geociências. São Paulo, v. 30, n 2, 2011.

SILVA, R. T.; PORTO, M. F. A. Gestão urbana e gestão das águas: caminhos da integração. Revista Estudos Avançados, São Paulo, v. 17, n. 47, p. 129-145, 2003.

TUNDISI, J. G., MATSUMURA-TUNDISI, T. Limnologia. São Paulo: Oficina de Textos, 2008.

VON SPERLING, M. Introdução à qualidade das águas e ao tratamento de esgotos. $3^{a}$ edição. Belo Horizonte: Departamento de Engenharia Sanitária e Ambiental, UFMG, 2005. 